\title{
A comparison of fitting techniques for ponderosa pine height-age models in British Columbia
}

\author{
Gordon NIGH* \\ Research Branch, BC Ministry of Forests, PO Box 9519, Stn. Prov. Govt., Victoria, BC, Canada V8W 9C2
}

(Received 28 April 2003; accepted 26 August 2003)

\begin{abstract}
The ponderosa pine height models currently in use in British Columbia, Canada, were calibrated for southwest Oregon, USA. Height growth patterns in British Columbia may be different from those in Oregon. Furthermore, they may be different between biogeoclimatic zones within British Columbia. To check this, 80 stem analysis plots were established to develop a new ponderosa pine height model. One tree in each 0.01 ha plot was intensively sampled to obtain annual heights from the pith nodes. A conditioned log-logistic function was used as the base height model. Various model fitting procedures were employed to meet assumptions about the data and the regressions. These procedures included using an autoregressive model to account for serial correlation, and using nonlinear mixed modelling so that site index could be treated as having a random component. The final version of the model tested for differences in height growth patterns across the four biogeoclimatic zones where ponderosa pine most often grows. Although growth differences between the zones were detected, the results may be uncertain due to small differences in height growth trajectories and small sample sizes for some zones. A new height model for ponderosa pine is now available for British Columbia. This model gives only slightly different height estimates from the current models, so the use of the previous model in the past has not led to poor forest management decisions.
\end{abstract}

height model / mixed effects model / nonlinear regression / site index / yellow pine

Résumé - Modèle de croissance en hauteur pour le pin ponderosa en Colombie-Britannique. Les modèles de croissance en hauteur pour le pin ponderosa actuellement en vigueur en Colombie-Britannique ont été mis au point pour le sud-ouest de l'Orégon. Les modèles de croissance en hauteur en Colombie-Britannique peuvent différer toutefois de ceux que l'on retrouve en Orégon. De plus, ils peuvent différer d'une zone biogéoclimatique à une autre à l'intérieur de la Colombie-Britannique. Afin de vérifier ceci, 80 placettes d'analyse de tige ont été réalisées afin de mettre au point un nouveau modèle de croissance en hauteur pour le pin ponderosa. Un arbre par placette de 0,01 ha a été échantillonné de façon détaillée dans le but d'obtenir les valeurs annuelles de hauteur à partir des verticilles. Une fonction logistique logarithmique a été adaptée et utilisée comme base du modèle de hauteur. Plusieurs procédures d'ajustement ont été utilisées afin de satisfaire les hypothèses concernant les données et les régressions. Ces procédures concernent l'utilisation d'un modèle d'autorégression afin de tenir compte de la corrélation en série ainsi que l'utilisation d'un modèle nonlinéaire mixte de façon à ce que l'indice de fertilité de station soit examiné en supposant la présence d'une composante aléatoire. La version finale du modèle a été testée pour des différences entre les modèles de croissance selon les quatre zones biogéoclimatiques où l'on retrouve plus fréquemment le pin ponderosa. Bien que des différences de croissance entre les zones ont été détectées, les résultats sont incertains en raison de petites différences dans les trajectoires de croissance et de la taille réduite de l'échantillon pour certaines zones. Un nouveau modèle de croissance en hauteur pour le pin ponderosa est maintenant disponible pour la Colombie-Britannique. Ce modèle fournit seulement des estimations de croissance en hauteur légèrement différentes si on le compare aux modèles actuellement utilisés, bien que l'utilisation du modèle précédent dans le passé n'a pas eu d'impact négatif sur les prises de décision en matière d'aménagement forestier.

modèle de croissance en hauteur / effets d'un modèle mixte / regression non linéaire / site index / Pinus ponderosa

\section{INTRODUCTION}

In British Columbia (BC), Canada, ponderosa pine (Pinus ponderosa Dougl. ex Laws) occurs frequently in the Ponderosa Pine (PP) and southern Interior Douglas-fir (IDF) biogeoclimatic zones [13, 17]. It also occurs infrequently in the Bunchgrass (BG) and southern Interior Cedar-Hemlock (ICH) zones $[13,14]$. These zones represent the northernmost limits of its range, which extends southward throughout the western United States and into Mexico [25].
A variety of height models exist for ponderosa pine. Dolph [7] developed models that estimate height increment for younger trees from site index and other variables, most importantly diameter increment. These models are not suitable, even after re-calibration, for many inventory and timber supply applications in BC because some predictor variables, such as individual tree diameter, are not available from the inventory. Height growth models for even-aged stands of ponderosa pine in the Pacific Northwest were developed by Barrett [2]. When Hann and Scrivani [10] compared their curves developed for ponderosa

\footnotetext{
* Corresponding author: Gordon.Nigh@gems5.gov.bc.ca
} 
pine in southwest Oregon to Barrett's curves, they found different height growth patterns between southwest Oregon and the Pacific Northwest. Milner [18] also found differences in height growth patterns when he compared his curve developed for western Montana to Barrett's, although he could not tell whether the differences were caused by genetics, methodology, or sampling. Milner did not compare his curves to Hann and Scrivani's. Stansfield and McTague [32] developed height and site index equations for ponderosa pine in east-central Arizona. They found that height growth patterns differed across habitat types $[1,5]$, which are roughly equivalent to ecological site series in $\mathrm{BC}$ [17].

British Columbia foresters use the model by Hann and Scrivani [10] to estimate the height and site index of ponderosa pine. The inconsistency in height growth patterns exhibited by the previously-mentioned studies indicates that localized models may need to be developed for British Columbia. Furthermore, site index ranges from about 19 to $34 \mathrm{~m}$ for the data used to develop the Hann and Scrivani models. This is much higher than the range found in British Columbia, which suggests that the Hann and Scrivani models may not be appropriate for British Columbia. The localization concept can be applied provincially or even to smaller areas, such as to biogeoclimatic zones. However, the need for localization is not a foregone conclusion [21]; it is an hypothesis that needs to be tested. The purpose of this research was to develop height-age models for ponderosa pine and to test for differences in height growth patterns between the four biogeoclimatic zones where ponderosa pine is most often found.

\section{MATERIALS AND METHODS}

Ponderosa pine stem analysis plots were established throughout the range of ponderosa pine in BC during the summers of 2000 and 2001. Sampling was directed to obtain plots that approximate the proportion of the abundance of the species in each biogeoclimatic zone. Plot establishment involved locating and monumenting plots, identifying the site tree, and classifying the ecosystem [15]. The target sample size was 100 plots of size 0.01 ha (5.64 m radius). This target was met, although 16 plots had to be rejected because some trees were too dangerous to fall, and other trees did not meet the site tree criteria upon a second inspection. Replacement plots were not established because the stem analysis sampling took place in the fall of 2001, which was too late in the field season for plant identification as is required for ecosystem classification.

One tree was selected in each plot as the site (sample) tree. This tree was the largest diameter dominant or co-dominant ponderosa pine tree in the plot. In order to reflect the site potential, it was also undamaged, unsuppressed, healthy, and vigorous. If a site tree was not available in the plot, then the plot was rejected as a stem analysis sample plot.

During the stem analysis sampling, each plot was re-visited and a diameter tally was taken for all trees in the plot. The site tree was inspected again to ensure that it met the requirements for a site tree, and if so, then it was felled, de-limbed, and its total height was measured. The height of a site tree is site height. A modified stem analysis technique was used. The tree was cut perpendicular to its length at approximately $40 \mathrm{~cm}$ intervals. The cuts went through the pith but not completely through the stem. Sledgehammers and wedges were used to knock the top half of the sections off the tree, revealing the pith. This was also done for the stump to get height growth down to the point of germination. The pith nodes, which identify annual height growth, were readily evident in the pith. Total height and age measurements were obtained from the pith nodes. At the top of the tree, the annual height growth was identified from branch whorls instead of pith nodes because the stem diameter was small, making splitting difficult. This technique has been used on smaller trees [22, 23].

Total ages were converted into breast height ages by subtracting the total age of the first pith node below breast height $(1.3 \mathrm{~m})$ from the total age of each node above breast height. Therefore, the first node above breast height had a breast height age of 1 . By definition, the height of the site tree at breast height age 50 was the site index. The height trajectory for each tree was plotted to detect erratic growth which indicates suppression or damage in the tree. Four trees were found to have erratic growth and were removed from further analyses. This left 80 trees for developing the height model.

The conditioned log-logistic function [33] was chosen for the site index model. A progression of increasingly complicated fitting techniques is presented to evaluate their impact on the resulting models. Researchers often test several models and choose the best one based on fit statistics such as the $R^{2}$ and mean squared error. Usually, though, the models have such similar fit statistics that in practical terms any of the tested models would suffice $[3,4,8,33]$. Therefore, I chose the log-logistic model because it was used successfully in the past for other species [3, 19,33], and because of its properties [20]. The form of this model is:

$$
\mathrm{H}=1.3+(\mathrm{SI}-1.3) \times \frac{1+\mathrm{e}^{\mathrm{b}_{0}-\mathrm{b}_{1} \times \ln (49.5)-\mathrm{b}_{2} \times \ln (\mathrm{SI}-1.3)}}{1+\mathrm{e}^{\mathrm{b}_{0}-\mathrm{b}_{1} \times \ln (\mathrm{BHA}-0.5)-\mathrm{b}_{2} \times \ln (\mathrm{SI}-1.3)}}+\varepsilon
$$

where $\mathrm{H}$ is site height (m), SI is site index (m), BHA is breast height age (yr), e is the base for natural logarithms, $\ln$ is the natural logarithm operator, $\varepsilon$ is a random error term, and $b_{i}(i=0,1,2)$ are model parameters. The constant 1.3 ensures that the model is asymptotic to 1.3 when breast height age approaches 0.5 . The constant 0.5 is subtracted from age to remove a bias caused by the tree reaching breast height midway through the growing season (not at breast height age 0 as is usually assumed; for more detail, see [20]). This model was fit to the heightbreast height age data using nonlinear least squares estimation and I made the usual assumptions about the random errors [26]. All statistical analyses were done with the SAS software [27]. These regression assumptions, for this and the following models, were tested with a $t$ test (expected value of $\varepsilon$ is zero), the W-statistic for normality [31], the lag-1 sample autocorrelation for independence [29, p. 279], and plots of $\varepsilon$ against site index and breast height age for homoscedasticity.

The basic model (1) usually does not adequately meet the regression assumptions. Therefore, I added a first-order autoregressive (AR(1)) error term to remove correlation between adjacent residuals. This often has the side-effect of reducing heteroscedasticity and nonnormality in the residuals. This led to model (2).

$$
\mathrm{H}=1.3+(\mathrm{SI}-1.3) \times \frac{1+\mathrm{e}^{\mathrm{b}_{0}-\mathrm{b}_{1} \times \ln (49.5)-\mathrm{b}_{2} \times \ln (\mathrm{SI}-1.3)}}{1+\mathrm{e}^{\mathrm{b}_{0}-\mathrm{b}_{1} \times \ln (\mathrm{BHA}-0.5)-\mathrm{b}_{2} \times \ln (\mathrm{SI}-1.3)}}+\phi \times \omega+\varepsilon
$$

where $\phi$ is the autocorrelation coefficient and $\omega$ is the error from the previous observation when the observations are ordered by plot and increasing breast height age ( $\omega$ is set to zero for the first observation in a plot). Parameter $\phi$ is estimated before fitting the model with the lag-1 sample autocorrelation [29, p. 279] calculated from the residuals in model (1). A different value of $\phi$ was estimated for each plot.

Height models have a deterministic and a stochastic part $(\varepsilon)$. The stochastic part represents random effects, for example, abnormal weather, height growth differences due to genetics, or microsite variation. Since site index is simply height at a specified age, then it has the same random effects as height. This suggests that the use of nonlinear mixed 
effects models [6] are more appropriate for modelling height. I re-fit model (1) but under the assumption that site index has a random component. This results in model (3).

$$
\mathrm{H}=1.3+(\mathrm{SI}+\delta-1.3) \times \frac{1+\mathrm{e}^{\mathrm{b}_{0}-\mathrm{b}_{1} \times \ln (49.5)-\mathrm{b}_{2} \times \ln (\mathrm{SI}+\delta-1.3)}}{1+\mathrm{e}^{\mathrm{b}_{0}-\mathrm{b}_{1} \times \ln (\mathrm{BHA}-0.5)-\mathrm{b}_{2} \times \ln (\mathrm{SI}+\delta-1.3)}}+\varepsilon
$$

where $\delta$ is a random component for site index. I assume that the $\delta$ s are normally distributed with mean zero and a constant, but unknown, variance. This model was fitted with nonlinear mixed effects software using maximum likelihood [27].

The next model that I fit is model (3) with an AR(1) term that models autocorrelation, resulting in model (4). This helps meet the assumption of independent error terms and hence makes the variances of the parameter estimates unbiased.

$$
\mathrm{H}=1.3+(\mathrm{SI}+\delta-1.3) \times \frac{1+\mathrm{e}^{\mathrm{b}_{0}-\mathrm{b}_{1} \times \ln (49.5)-\mathrm{b}_{2} \times \ln (\mathrm{SI}+\delta-1.3)}}{1+\mathrm{e}^{\mathrm{b}_{0}-\mathrm{b}_{1} \times \ln (\mathrm{BHA}-0.5)-\mathrm{b}_{2} \times \ln (\mathrm{SI}+\delta-1.3)}}+\phi \times \omega+\varepsilon .
$$

Parameter $\phi$ is estimated before fitting the model with the lag-1 sample autocorrelation calculated from the residuals in model (3). A different value of $\phi$ was estimated for each plot.

For the final model, I tested for differences in height growth patterns between the four biogeoclimatic zones that were sampled. Parameters $b_{0}, b_{1}$, and $b_{2}$ were expressed as linear functions of indicator variables for the four zones that were sampled, resulting in model (5). Indicator variables modify the value of these parameters depending on which zone the tree came from. I was unable to test for differences between subzone/variants (areas within zones differentiated by climatic variations) because some variants only had 1 plot.

$\mathrm{H}=1.3+(\mathrm{SI}+\delta-1.3) \times \frac{1+\mathrm{e}^{\mathrm{b}_{0}-\mathrm{b}_{1} \times \ln (49.5)-\mathrm{b}_{2} \times \ln (\mathrm{SI}+\delta-1.3)}}{1+\mathrm{e}^{\mathrm{b}_{0}-\mathrm{b}_{1} \times \ln (\mathrm{BHA}-0.5)-\mathrm{b}_{2} \times \ln (\mathrm{SI}+\delta-1.3)}}+\phi \times \omega+\varepsilon$

where $b_{0}=b_{01}+b_{02} \times I C H+b_{03} \times I D F+b_{04} \times P P, b_{1}=b_{11}+b_{12} \times$ $\mathrm{ICH}+\mathrm{b}_{13} \times \mathrm{IDF}+\mathrm{b}_{14} \times \mathrm{PP}, \mathrm{b}_{2}=\mathrm{b}_{21}+\mathrm{b}_{22} \times \mathrm{ICH}+\mathrm{b}_{23} \times \mathrm{IDF}+\mathrm{b}_{24} \times$ $\mathrm{PP}$, and ICH, IDF, and PP are indicator variables that take on the value of 1 if the plot is in the respective zone, 0 otherwise. This model was fit using the same method as model (4). Parameter $\phi$ is estimated before fitting the model with the lag-1 sample autocorrelation from fitting model (5) without the autoregressive model. This fitting was done strictly to estimate $\phi$. A different value of $\phi$ was estimated for each plot.

Differences in height growth patterns between zones were tested using indicator variables. Parameters that were not significantly different from each other were consolidated into one parameter. For example, if parameters $b_{02}$ and $b_{03}$ were not significantly different from each other, then a new parameter, denoted $b_{023}$, was used in place of $b_{02}$ and $b_{03}$ and the model was re-fit. Parameter $b_{i 1}, i=0,1$, or 2 , represents the BG zone. Since maximum likelihood was used to estimate the parameters, the likelihood ratio test [12] was used to test the significance of the parameters. Parameter consolidation only occurred within the equations for $b_{0}, b_{1}$, and $b_{2}$. That is, parameter $b_{i j}$ was not consolidated with parameter $b_{m n}$ if $i \neq m$.

I was interested in seeing how the models I developed differed from each other. Since the same data were used for all models, any differences would be attributable to the fitting technique and/or model differences. For comparison purposes, models (1)-(4) were graphed together. I also graphed model (5) for the 4 zones to get a sense of how growth patterns differed across zones. Finally, I graphed model (4) and the ponderosa pine model by Hann and Scrivani [10], which is the model currently recommended for use in $\mathrm{BC}$, to give some indication as to how much difference in growth patterns there is between geographic regions. This comparison will also show how much impact changing models will have on height estimates.

\section{RESULTS}

Table I presents summary statistics for total age, breast height age, height, and site index. Statistics shown include number of observations, mean, minimum, maximum, and median. Generally, the heights and site indexes were normally distributed, but total age and breast height age were not.

The results of the fitting of the five models varied from model to model. Generally, the AR(1) model and the mixed effects modelling approach improved the statistical properties of the model, and this is evident from the fit statistics and the statistics/graphics used to test the regression assumptions.

The parameter estimates, mean error, root mean squared error, W-statistic, and mean value for $\phi$ for the 80 plots for models (1), (2), (3), and (4) are shown in Table II. The mean error for model (1) indicates that it is slightly biased, but the mean error for the other models are not significantly different from 0 . There is evidence that all four models do not meet the normality assumption. However, the power of the $\mathrm{W}$ test increases with increasing sample size, making a small departure from normality detectable. The large value for $\mathrm{W}$ indicates that the residuals are nearly normally distributed, and slight departures from normality do not generally have much impact on statistical tests ([16], p. 541). The average values for $\phi$ are large, indicating that adjacent residuals are correlated, but $\phi$ is greatly reduced by the addition of the $\mathrm{AR}(1)$ model and the use of the mixed model. The plots of the residuals (not shown to conserve space) for model (1) showed obvious heteroscedasticity and correlation in the residuals. The plots for model (2) showed much improved statistical properties, as there was little evidence of heteroscedasticity and correlation. Some heteroscedasticity and correlation was apparent in model (3) but not for model (4).

The statistical properties of model (4) were better than the other three models. It had the lowest mean error and mean squared error. These are measures of bias and precision, respectively. It also had the largest $\mathrm{W}$-statistic for normality and the lowest average $\phi$ of the four models. Furthermore, the plots of the residuals against predicted height, age, and site index showed the least evidence of heteroscedasticity and correlation in the residuals out of all four models. Therefore, model (4) most closely met the regression assumptions and consequently is the preferred model of these four for estimating height and site index for ponderosa pine in British Columbia.

The final model (5) tests for differences in height growth patterns across different biogeoclimatic zones. After combining parameters that weren't significantly different, parameters $b_{0}$, $b_{1}$, and $b_{2}$ reduced to $b_{0}=b_{0234} \times(I C H+I D F+P P), b_{1}=b_{114}+$ $b_{12} \times I C H+b_{13} \times I D F$, and $b_{2}=b_{21}+b_{22} \times I C H+b_{234} \times$ $(\mathrm{IDF}+\mathrm{PP})$. The parameter estimates for this model are presented in Table III. The mean error and root mean squared error for this model are $0.003687(p=0.68)$ and 0.3720 , respectively. The W-statistic was $0.9966(p=0.0009)$ and $\phi$ averaged 0.496 . These statistics indicate an improvement over model (4). 
Table I. Summary statistics for total age, breast height age, height, and site index.

\begin{tabular}{|c|c|c|c|c|c|c|}
\hline Zone & Character & $\mathrm{N}$ & Mean & Median & Minimum & Maximum \\
\hline \multirow[t]{4}{*}{ BG } & Total age (yrs) & 6 & 123 & 113 & 104 & 156 \\
\hline & Breast height age (yrs) & 6 & 107 & 95 & 90 & 142 \\
\hline & Height (m) & 6 & 22.19 & 22.80 & 18.40 & 24.85 \\
\hline & Site index (m) & 6 & 12.36 & 12.53 & 9.41 & 14.57 \\
\hline \multirow[t]{4}{*}{$\mathrm{ICH}$} & Total age (yrs) & 3 & 122 & 121 & 98 & 148 \\
\hline & Breast height age (yrs) & 3 & 114 & 115 & 87 & 140 \\
\hline & Height (m) & 3 & 35.09 & 38.24 & 27.51 & 39.51 \\
\hline & Site index (m) & 3 & 19.70 & 21.22 & 16.26 & 21.61 \\
\hline \multirow[t]{4}{*}{ IDF } & Total age (yrs) & 47 & 133 & 120 & 83 & 243 \\
\hline & Breast height age (yrs) & 47 & 119 & 108 & 74 & 227 \\
\hline & Height (m) & 47 & 25.49 & 25.71 & 13.01 & 37.71 \\
\hline & Site index (m) & 47 & 13.38 & 13.21 & 5.01 & 21.72 \\
\hline \multirow[t]{4}{*}{ PP } & Total age (yrs) & 24 & 118 & 112 & 84 & 206 \\
\hline & Breast height age (yrs) & 24 & 105 & 99 & 77 & 183 \\
\hline & Height (m) & 24 & 22.76 & 22.53 & 14.74 & 32.40 \\
\hline & Site index (m) & 24 & 13.74 & 13.17 & 8.99 & 24.78 \\
\hline \multirow[t]{4}{*}{ All } & Total age (yrs) & 80 & 128 & 119 & 83 & 243 \\
\hline & Breast height age (yrs) & 80 & 114 & 106 & 74 & 227 \\
\hline & Height $(m)$ & 80 & 24.78 & 23.71 & 13.01 & 39.51 \\
\hline & Site index (m) & 80 & 13.65 & 13.33 & 5.01 & 24.78 \\
\hline
\end{tabular}

BG: Bunchgrass zone; ICH: Interior Cedar-Hemlock zone; IDF: Interior Douglas-fir zone; PP: Ponderosa Pine zone.

Table II. Results of the analysis of models (1), (2), (3), and (4).

\begin{tabular}{|c|c|c|c|c|c|c|}
\hline Model & Parameter & Parameter estimate & Mean error (m) & RMSE & W & $\phi$ \\
\hline \multirow[t]{5}{*}{ (1) } & $\mathrm{b}_{0}$ & $\begin{array}{c}9.916 \\
(0.0733)\end{array}$ & $\begin{array}{c}0.1429 \\
(p<0.0001)\end{array}$ & 1.476 & $\begin{array}{c}0.9578 \\
(p<0.0001)\end{array}$ & 0.848 \\
\hline & $\mathrm{b}_{1}$ & 1.596 & & & & \\
\hline & & $(0.0241)$ & & & & \\
\hline & $\mathrm{b}_{2}$ & 1.191 & & & & \\
\hline & & $(0.0256)$ & & & & \\
\hline \multirow[t]{6}{*}{ (2) } & $\mathrm{b}_{0}$ & 9.202 & -0.005554 & 0.4102 & 0.9934 & 0.553 \\
\hline & & $(0.113)$ & $(p=0.58)$ & & $(p<0.0001)$ & \\
\hline & $\mathrm{b}_{1}$ & 1.422 & & & & \\
\hline & & $(0.0197)$ & & & & \\
\hline & $\mathrm{b}_{2}$ & 1.080 & & & & \\
\hline & & $(0.0433)$ & & & & \\
\hline \multirow[t]{6}{*}{ (3) } & $\mathrm{b}_{0}$ & 8.930 & 0.01757 & 0.9297 & 0.9917 & 0.771 \\
\hline & & $(0.0918)$ & $(p=0.42)$ & & $(p<0.0001)$ & \\
\hline & $\mathrm{b}_{1}$ & 1.438 & & & & \\
\hline & & $(0.0165)$ & & & & \\
\hline & $\mathrm{b}_{2}$ & 0.9579 & & & & \\
\hline & & $(0.0311)$ & & & & \\
\hline \multirow[t]{6}{*}{ (4) } & $\mathrm{b}_{0}$ & 8.519 & 0.002363 & 0.3818 & 0.9972 & 0.515 \\
\hline & & $(0.132)$ & $(p=0.79)$ & & $(p<0.0040)$ & \\
\hline & $\mathrm{b}_{1}$ & 1.385 & & & & \\
\hline & & $(0.0178)$ & & & & \\
\hline & $\mathrm{b}_{2}$ & 0.8498 & & & & \\
\hline & & $(0.0472)$ & & & & \\
\hline
\end{tabular}

The standard error of the parameter estimates are in parentheses below the estimate; the $p$-value for the mean error and $\mathrm{W}$ statistics are in parentheses below the statistic; RMSE: root mean squared error. 
Table III. Parameter estimates and their standard errors for model (5).

\begin{tabular}{lccc}
\hline Parameter & Zone(s) & Estimate & $\begin{array}{c}\text { Standard } \\
\text { error }\end{array}$ \\
\hline $\mathrm{b}_{0234}$ & ICH, IDF, and PP & 8.829 & 0.132 \\
$\mathrm{~b}_{114}$ & All & 1.516 & 0.0207 \\
$\mathrm{~b}_{12}$ & ICH & -0.4994 & 0.0471 \\
$\mathrm{~b}_{13}$ & IDF & -0.08833 & 0.0119 \\
$\mathrm{~b}_{21}$ & All & -2.790 & 0.0443 \\
$\mathrm{~b}_{22}$ & ICH & 3.898 & 0.0753 \\
$\mathrm{~b}_{234}$ & IDF and PP & 3.697 & 0.0653 \\
\hline
\end{tabular}

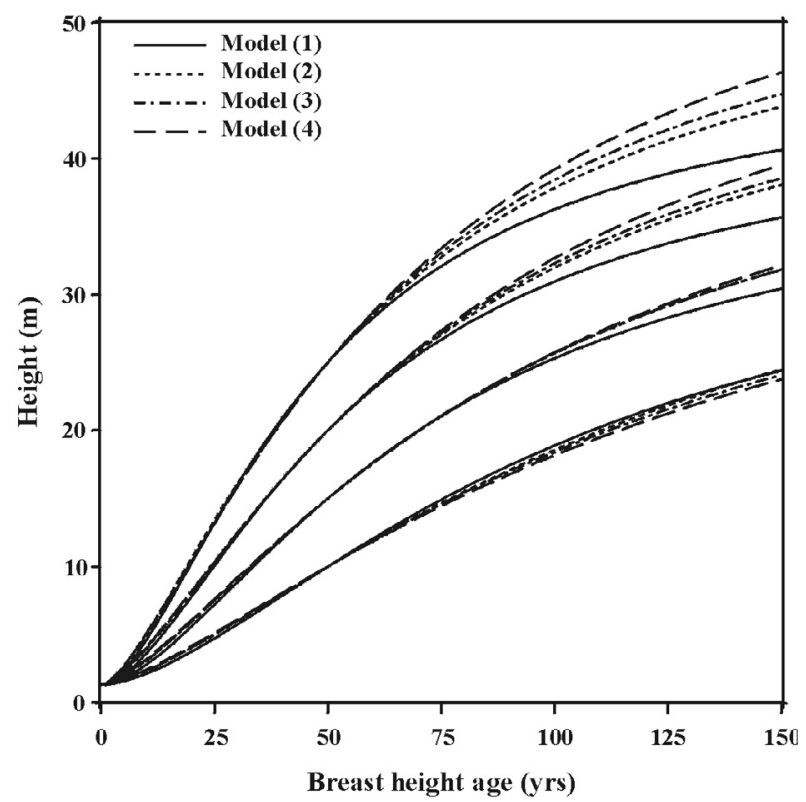

Figure 1. Height estimates from models (1), (2), (3), and (4) plotted against breast height age for site indices $10,15,20$, and $25 \mathrm{~m}$. This figure shows the differences in height estimates from the four models.

As well, the residual plots showed little or no heteroscedasticity or correlation amongst the residuals. The analysis of the indicator variables indicates that the growth patterns for all of the zones are statistically different.

Figure 1 shows estimated heights (m) from models (1), (2), (3), and (4) plotted against breast height age (yr) for site indices $10,15,20$, and $25 \mathrm{~m}$ at breast height age 50. It appears that the different parameter estimation techniques lead to substantially different curves at ages above approximately $100 \mathrm{yr}$ and for higher site indices. However, the distribution of the data shows that the curve shapes are not well-supported by data at older ages and higher site indices. The curves for site indices 10 and $15 \mathrm{~m}$ have a reasonable amount of data up to and past age 150 . There is only one plot with a site index around $20 \mathrm{~m}$ that is older than $125 \mathrm{yr}$. The different analysis techniques give a different weight to the data from this plot. Therefore, the different curve shapes are likely due to one plot. There is only one plot with a site index around $25 \mathrm{~m}$, and its age is about $75 \mathrm{yr}$. A further con-
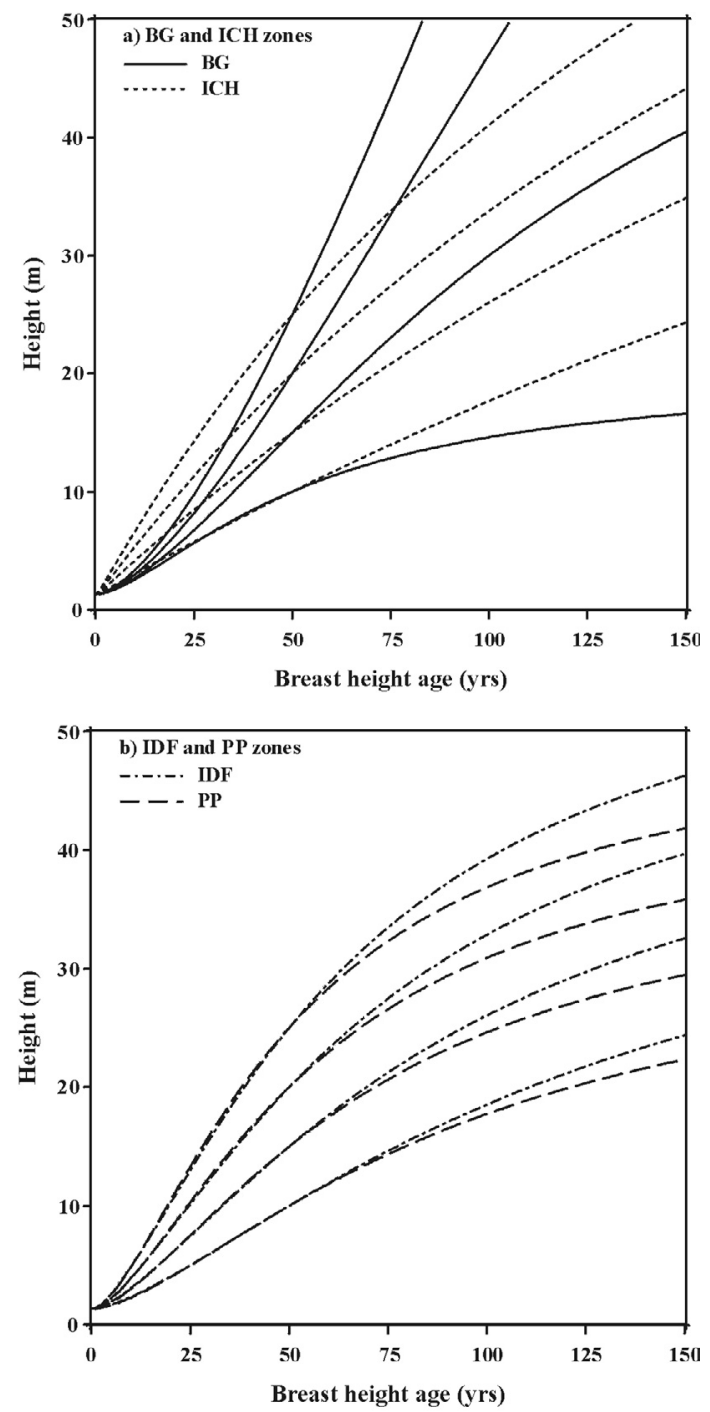

Figure 2. Height estimates from model (5) plotted against breast height age for site indices $10,15,20$, and $25 \mathrm{~m}$. This figure shows the difference in height estimates between the four biogeoclimatic zones that were sampled: BG and ICH - part a; IDF and PP - part b.

sideration when graphically comparing curve shapes is that the shapes are often visually different but may not be statistically different.

Figure 2 shows the modelled height trajectories from model (5) for the plots in the BG and ICH zones (part a) and the IDF and PP zones (part b). This figure is split into 2 parts to illustrate a problem with the curves for the BG and ICH zones. Although the fit to the height trajectory for the plots in these zones was satisfactory, the resulting model is not satisfactory. The parameters for the ICH zone are based on three plots, which is too small of a sample on which to make inferences. These plots were young and hence did not display a strong asymptotic behaviour. This led to the curves being almost linear, and probably not accurate beyond the range of the data. The parameters for the BG zone are based on more plots. Some of these plots had unusual height growth patterns, but not unusual enough to 


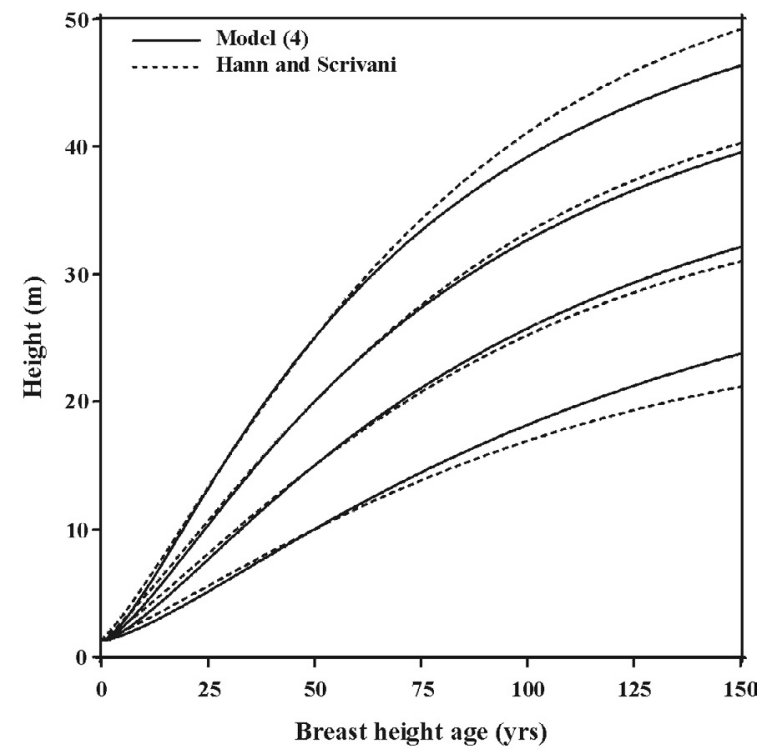

Figure 3. Height estimates from model (4) and the Hann and Scrivani [10] model plotted against breast height age for site indices 10,15 , 20 , and $25 \mathrm{~m}$. This figure shows the difference in height estimates between the two models.

invalidate their status as a site tree. The BG zone is very dry and these height growth patterns could have been caused by site conditions. These few plots caused the unusual height trajectories for the BG zone in Figure 2a. Note that sites with a site index of 20 or $25 \mathrm{~m}$ in the BG zone probably do not exist and the curves shown in Figure 2a for site index 20 and 25 are based on extrapolated data. Height growth in the IDF zone does not differ much from height growth in the PP zone, particularly at younger ages and on lower sites (Fig. 2b). The height growth in the PP zone, however, slows faster at older ages than in the IDF, particularly at higher site indices. The divergence of the two curves occurs where there is little or no data. Consequently, there is some data to support the evidence that there is a difference in the height growth patterns between the IDF and PP zones, but the evidence is not conclusive.

Figure 3 is a comparison between model (4) and the Hann and Scrivani [10] model. Model (4) produces lower height estimates below the index age and on better sites. It has higher heights on poorer sites above the index age. The trajectories of the two curves are similar in the mid to high site index range, which is likely the most important range because there are few high sites, and harvesting and management will not be targeted at the lower sites.

\section{DISCUSSION}

The BC Ministry of Forests currently recommends that the site index models developed by Hann and Scrivani [10] be used to estimate the height and site index of ponderosa pine in $\mathrm{BC}$ This research provides an alternative model that is based on data collected in BC using local standards for site index research. Model (5) had the best statistical properties and had the lowest mean squared error of the 5 models tested. However, its height predictions are unreliable when extrapolated, especially for the BG and ICH zones. Model (4) had the smallest mean error and its mean squared error was almost as small as that for model (5). Therefore, I recommend the use of model (4) for estimating the height of ponderosa pine in British Columbia. The models cannot be algebraically inverted to predict site index from height and age, but site index can be obtained from the models using iterative techniques [35].

It is critically important to have good growth and yield information for sustainable forest management of ponderosa pine since it is not an easy species to regenerate. It is difficult to establish because of drought at critical times in the growing season, competing vegetation, animal damage and predation, seedling quality, and frost heaving [11]. Natural regeneration is particularly difficult because it depends on a good seed source, adequate moisture, and lack of competing vegetation all occurring simultaneously [9]. Poor growth and yield information coupled with the species' regeneration difficulties may lead to unsustainable forest management. This height model is a key component for obtaining good estimates of the growth and yield of ponderosa pine.

Four variations of the logistic model were fit to the data. In each variation, the basic model remained the same while different assumptions about the error structure were modelled in each variant. The parameter estimates changed from variant to variant, but the shape of the curves only changed marginally, at least within the range of the of the data.

The statistical analysis shows that height growth patterns for ponderosa pine in the $\mathrm{BG}, \mathrm{ICH}$, IDF and PP biogeoclimatic zones were different (Tab. III). The difference is not conclusive for the BG and ICH zones due to a small number of plots in these zones. The BG zone is the driest in the province and the ICH zone is the one of the wettest and most productive in the province [17]. Therefore, I expected that growth differences would be more likely in these two zones. However, differing levels of soil moisture does not necessarily impact height growth patterns [34]. Although the curves for the IDF and PP zones differ, the differences are small within the range of the data (Fig. 2, and note that the divergence of the curves occurs outside of the range of the most of the data). Overall, then, the analysis does not conclusively show height growth differences between biogeoclimatic zones. Model (4) is more robust and should be used for height estimates.

The Hann and Scrivani [10] curves are similar to model (4) (Fig. 3). When comparing the curves the range of the data must be taken into consideration and also there are no confidence intervals to indicate statistical differences. Discrepancies are evident at young ages and at old ages, particularly for the high and low sites. These are small, however, and therefore the Hann and Scrivani curves should have given reasonable height and site index estimates in the past.

Comparing models graphically is often done in the literature but may lead to wrong conclusions. Conclusively detecting differences in tree height growth between two biogeoclimatic zones (as an example, but it may also be done for elevation or other variables) cannot be done by plotting estimated heights for a given level of site index, and claiming a difference if the two lines are not identical. This method does not take into account the natural variability in height growth patterns and 
sampling error. A better comparison could be made by plotting the confidence intervals for the two lines. However, even this is not a rigorous procedure because the regression assumptions in the development of the model are often violated, which leads to biased estimates of the variance and hence biased confidence intervals [30]. Furthermore, testing for statistical significance using overlapping confidence intervals does not always lead to the correct conclusion [28]. Obtaining good confidence intervals for comparison or validation purposes is not easy [24]. The other major problem with graphically comparing height trajectories is that often the stem analysis data are not balanced; older plots are usually available from poorer sites with lower site indices. Comparing estimated height trajectories without data to support the trajectory may be misleading. In my experience, different model fitting techniques dramatically alters the height trajectories beyond the range of the data [20]. Therefore, differences in curve shapes in extrapolated ranges may be due to the data analysis technique rather than to biological differences.

\section{CONCLUSION}

The height of ponderosa pine is effectively estimated from site index and breast height age using model (4). This model is calibrated specifically for British Columbia conditions, and in that respect is an improvement over the Hann and Scrivani curves, which were calibrated for southwest Oregon. However, despite the difference in the sources of data, the two curves are quite similar. Differences in height growth patterns between biogeoclimatic zones were detected but not conclusive and are small over the range of the data.

Acknowledgements: This research was funded by Forest Renewal B.C. Dr Ken Mitchell, British Columbia Ministry of Forests, provided helpful review comments.

\section{REFERENCES}

[1] Alexander R.R., Major habitat types, community types, and plant communities in the Rocky Mountains, US For. Serv. Rocky Mt. For. Range Exp. Stn. Gen. Tech. Rep. RM-123, 1985.

[2] Barrett J.W., Height growth and site index curves for managed, even-aged stands of ponderosa pine in the Pacific Northwest, USDA Forest Service Research Paper PNW-232, 1978.

[3] Chen H.Y.H., Klinka K., Height growth models for high-elevation subalpine fir, Engelmann spruce, and lodgepole pine in British Columbia, West. J. Appl. For. 15 (2000) 62-69.

[4] Chen H.Y.H., Klinka K., Kabzems R.D., Height growth and site index models for trembling aspen (Populus tremuloides Michx.) in northern British Columbia, For. Ecol. Manage. 102 (1998) 157-165.

[5] Daubenmire R., The use of vegetation in assessing the productivity of forest lands, Bot. Rev. 42 (1976) 115-143.

[6] Davidian M., Giltinan D.M., Nonlinear models for repeated measurement data, Chapman \& Hall, London, 1995.

[7] Dolph K.L., Predicting height increment of young-growth mixed conifers in the Sierra Nevadas, USDA Forest Service Research Paper PSW-191, 1988.

[8] Elfving B., Kiviste A., Construction of site index equations for Pinus sylvestris L. using permanent plot data in Sweden, For. Ecol. Manage. 98 (1997) 125-134.

[9] Foiles M.W., Curtis J.D., Natural regeneration of ponderosa pine on scarified group cuttings in central Idaho, J. For. 63 (1965) 530-535.

[10] Hann D.W., Scrivani J.A., Dominant-height-growth and site-index equations for Douglas-fir and ponderosa pine in southwest Oregon,
Oregon State University, Forest Research Laboratory, Corvallis, Oregon, Res. Bull. 59, 1987.

[11] Heidmann L.J., Ponderosa pine regeneration in the southwest, in Foresters' future: leaders or followers? Proceedings of the Society of American Foresters National Convention 1985, Society of American Foresters, Washington, DC, 1985, pp. 228-232.

[12] Kalbfleisch J.G., Probability and statistical inference, Vol. 2, Statistical inference, Springer-Verlag Inc., New York, 1985.

[13] Klinka K., Worrall J., Skoda L., Varga P., The distribution and synopsis of ecological and silvical characteristics of tree species of British Columbia's forests, Canadian Cartographics Ltd., Coquitlam, BC, 2000.

[14] Lloyd D., Angrove K., Hope G., Thompson C., A guide to site identification and interpretation for the Kamloops Forest Region, BC Ministry of Forests, Research Branch, Victoria, BC Land Management Handbook Number 23, 1990.

[15] Luttmerding H.A., Demarchi D.A., Lea E.C., Meidinger D.V., Vold T. (Eds.), Describing ecosystems in the field, 2nd ed., BC Ministry of Environment, Lands and Parks, Victoria, BC, Ministry of the Environment Manual 11, 1990.

[16] Mason R.L., Gunst R.F., Hess J.L., Statistical design and analysis of experiments with applications to engineering and science, John Wiley \& Sons, Inc., New York, 1990.

[17] Meidinger D., Pojar J., Ecosystem of British Columbia, BC Ministry of Forests, Research Branch, Victoria, BC Special Report Series Number 6, 1991.

[18] Milner K.S., Site index and height growth curves for ponderosa pine, western larch, lodgepole pine, and Douglas-fir in western Montana, West. J. Appl. For. 7 (1992) 9-14.

[19] Monserud R.A., Height growth and site index curves for inland Douglas-fir based on stem analysis data and forest habitat type, For. Sci. 30 (1984) 943-965.

[20] Nigh G.D., A Sitka spruce height-age model with improved extrapolation properties, For. Chron. 73 (1997) 363-369.

[21] Nigh G.D., Species-independent height-age models for British Columbia, For. Sci. 47 (2001) 150-157.

[22] Nigh G.D., Love B.A., A model for estimating juvenile height of lodgepole pine, For. Ecol. Manage. 123 (1999) 157-166.

[23] Nigh G.D., Love B.A., Juvenile height development in interior spruce stands of British Columbia, West. J. Appl. For. 15 (2000) 117-121.

[24] Nigh G.D., Sit V., Validation of forest height-age models, Can. J. For. Res. 26 (1996) 810-818.

[25] Oliver W.W., Ryker R.A., Ponderosa pine, in: Burns R.M., Honkala B.H. (Techn. Coords.), Silvics of North America, Vol. 1, Agriculture Handbook 654, USDA Forest Service, Washington, DC, 1990, pp. 413-424.

[26] Ratkowksy D.A., Nonlinear regression modeling, Marcel Dekker, Inc., New York, 1983.

[27] SAS Institute Inc., SAS OnlineDoc ${ }^{\circledR}$, Version 8, Cary, NC, 1999.

[28] Schenker N., Gentleman J.F., On judging the significance of differences by examining the overlap between confidence intervals, Am. Stat. 55 (2001) 182-186.

[29] Seber G.A.F., Wild C.J., Nonlinear regression, John Wiley \& Sons, Inc. Toronto, 1989.

[30] Sen A.K., Srivastava M., Regression analysis: theory, methods, and applications, Springer-Verlag, New York, Inc., New York, 1990.

[31] Shapiro S.S., Wilk M.B., An analysis of variance test for normality (complete samples), Biometrika 52 (1965) 591-611.

[32] Stansfield W.F., McTague J.P., Dominant-height and site-index equations for ponderosa pine in east-central Arizona, Can. J. For. Res. 21 (1991) 606-611.

[33] Thrower J.S., Goudie J.W., Estimating dominant height and site index of even-aged interior Douglas-fir in British Columbia, West. J. Appl. For. 7 (1992) 20-25.

[34] Wang G.G., Marshall P.L., Klinka K., Height growth pattern of white spruce in relation to site quality, For. Ecol. Manage. 68 (1994) 137-147.

[35] Wang Y., Payandeh B., A numerical method for the solution of a base-age-specific site index model, Can. J. For. Res. 23 (1993) 2487-2489. 